\title{
EL DERECHO A LA IDENTIDAD Y EL REGISTRO NACIONAL DE CEDENTES DE GAMETOS Y EMBRIONES
}

\author{
THE RIGHT OF IDENTITY AND THE NATIONAL REGISTER OF DONORS \\ OF GAMETES AND EMBRYOS
}

Rose Mary Posadas Gutiérrez ${ }^{1}$

\section{Resumen}

Las técnicas de reproducción humana asistida son un medio para tratar la infertilidad humana y favorecer la procreación; sin embargo, para su aplicación en determinados casos, se requiere de personas que donen sus gametos (esperma u óvulo) para posibilitar la concepción del hijo (a) de la pareja que hace uso de estas técnicas de reproducción.

Actualmente, el Perú no cuenta con un registro único y centralizado de donantes de gametos ni la cantidad de nacidos a través de estas técnicas de reproducción con el material genético de estos donantes. Urge, por tanto, determinar la necesidad de tal registro.

En el presente artículo se presenta y confronta la necesidad de dicho registro no sólo desde el ámbito de la salud del donante, sino fundamentalmente, de la afectación al derecho a la identidad del nacido de estas técnicas.

Palabras clave: Técnicas de Reproducción Humana Asistida, bioética, donante, derecho a la identidad.

\section{Abstract}

Assisted human reproduction (AHR) techniques are a means to treat human infertility and promote procreation; however, in certain cases, it is necessary for people to donate their gametes (sperm or ovum) to enable the conception of a child of the couple that uses these reproduction techniques.

Maestra en Derecho Civil con mención de Derecho de Familia de la UNIFÉ, docente de la Escuela de Derecho de la Universidad Cesar Vallejo, así como lo ha sido en la Facultad de Derecho de la UNIFÉ y en la Escuela de Oficiales de la PNP. Abogada de la Gerencia de Registros Civiles del RENIEC.

Email: romypg32@hotmail.com 
Currently, Peru does not have a single and centralized register of gametes donors or the number of children born through these techniques of reproduction with the genetic material of these donors. It is therefore urgent to determine the need for such a register. This article presents and confronts the need for such a register not only from the donor's health point of view, but also, fundamentally, from the violation of the right to identity of those born through these techniques.

Keywords: Assisted Human Reproduction Techniques, bioethics, donor, right to identity.

\section{INTRODUCCIÓN}

Las Técnicas de Reproducción Humana Asistida - TERAS tienen por finalidad fundamental la actuación médica ante la esterilidad y la infertilidad humana, intentando facilitar la procreación cuando otras terapias clínicas se han descartado por ineficaces (Valverde, 2001). En virtud a ello, son de dos tipos: Inseminación Artificial, que consiste en introducir semen previamente recolectado en el aparato reproductor femenino; y Fecundación Extrauterina, que consiste en lograr la fecundación de un óvulo fuera del cuerpo de la mujer, para luego implantar el embrión en su aparato reproductor. Ambas técnicas a su vez pueden ser homólogas, si los gametos proceden de la misma pareja, o heterólogas si los gametos proceden de algún tercero ajeno a la misma (Mosquera, 2010.)

De acuerdo a la información contenida en las Guías Nacionales de Atención Integral de la Salud Sexual y Reproductiva, más del 10\% de la población tiene algún tipo de problema de infertilidad; de ahí que el uso de las Técnicas de Reproducción Humana Asistida se constituye como un medio necesario para procrear hijos.

En el Perú, de acuerdo a estadísticas no oficiales, el número de fertilizaciones in vitro es de los más elevados de la región, con tres mil procedimientos al $\mathrm{año}^{2}$; información que puede ser complementada con la publicada por la Red Latinoamericana de Reproducción Asistida ${ }^{3}$ en el Primer Registro Multinacional caso a caso a mayo de 2013, que arroja en nuestro país un total de 4,927 niños nacidos mediante TERAS, según la información reportada por las clínicas adscritas a dicha Red.

Revista SOMOS de El Comercio, Año XXIII N 1249, “Te daré la vida”, pag. 61.

La Red Latinoamericana de Reproducción Asistida (RED) (www.redlara.com), es una institución científica y educacional, que reúne más del $90 \%$ de los centros que realizan técnicas de reproducción asistida en Latinoamérica, formada en 1995, con la participación de 50 centros y, actualmente tiene 166 centros adscritos. Posee el Registro Latinoamericano de Reproducción Asistida (RLA), que anualmente cataloga todos los resultados de las técnicas de reproducción asistida reportados por estos centros. En el caso del Perú se encuentran adscritos el Centro de Fertilidad y Reproducción Asistida, Clínica Miraflores, FERTILAB, Grupo PRANOR y NACER. 


\section{Inexistencia de estadísticas oficiales de la cantidad de procedimientos de Técnicas de Reproducción Humana Asistida}

Conforme a la Ley General de Salud, las atenciones de salud brindadas a los pacientes, deben colocarse obligatoriamente en una historia clínica, que se constituye en el documento médico legal en el que se registran los datos de identificación y de los procesos relacionados con la atención del paciente en forma ordenada, integrada, secuencial e inmediata de la atención que el médico u otros profesionales de salud brindan al paciente que se conserva en el Centro de Salud donde se atendió el paciente.

Con motivo de consolidar dicha información, mediante Ley № $30024^{4}$ se ha creado el Registro Nacional de Historias Clínicas Electrónicas como la infraestructura tecnológica especializada en salud que permita al paciente $o$ a su representante legal y a los profesionales de la salud que son previamente autorizados por aquellos, el acceso a la información clínica contenida en las historias clínicas dentro de los términos estrictamente necesarios para garantizar la calidad de la atención en los establecimientos de salud y en los servicios médicos de apoyo públicos, privados o mixtos. En el caso de la atención materna, existe el Formato de la Historia Clínica Perinatal Básica que contiene, entre otros datos, los de identificación de la paciente, antecedentes personales, obstétricos y familiares, datos y exámenes del embarazo, parto o aborto ${ }^{5}$, que se conserva en el Centro de Salud en donde se atendió el paciente; y que por su naturaleza es de carácter reservado sólo al personal médico que brinda la atención y al paciente.

Tratándose del nacido en sí, el profesional de la salud extiende además, el Certificado de Nacido Vivo, que es el único documento a nivel nacional que contiene información estadística de los nacidos, que sirve de base al Ministerio de Salud para elaborar sus indicadores por grupos etarios y por regiones; así como la cantidad de atenciones y de morbilidad; que a nivel informativo obra en la página web de dicha institución. La información estadística allí contenida es pública, y no tiene carácter reservado, de ahí que no se requiera al administrado para dar su conformidad con la divulgación de la misma; como si sucede en las historias clínicas.

Sin embargo, conforme se puede apreciar, en la parte desglosable del Informe Estadístico del nacido vivo no existe ningún rubro destinado a la procreación del nacido, sea de forma natural o mediante el uso de Técnicas de Reproducción Humana Asistida, situación que no sólo no permite conocer la

Ley N ${ }^{\circ}$ 30024, Ley que crea el Registro Nacional de Historias Clínicas Electrónicas, publicada el 22 de mayo de 2013. N.T. N ${ }^{\circ} 22-M I N S A / D G S P-V .02$, Norma Técnica de la Historia Clínica de los Establecimientos del sector salud. 
cantidad de intervenciones de este tipo que se realizan y la cantidad de niños nacidos como consecuencia de ello, sino tampoco el tipo de establecimiento en el cual se realizan.

Además, debe tenerse en cuenta que la información estadística en el caso de estos nacidos, permitiría conocer cuántas parejas sufren de problemas de infertilidad y acuden al uso de técnicas de reproducción asistida para poder ser padres; cuántos de estos niños nacen de sus padres biológicos pero asistidos de la ciencia médica (TERAS Homólogas); y cuántos nacen con la ayuda de un donante (TERAS Heterólogas), e incluso cuántos lo hacen en el vientre de una madre sustituta; información que serviría de base no sólo para la toma de decisiones en el sector salud; sino también en el ámbito del sector justicia para emitir la normativa legal que atienda esta problemática que viene siendo resuelta en el Poder Judicial por los jueces en aplicación del control difuso de la norma constitucional para no vulnerar los derechos de los nacidos de estas técnicas.

Pero el problema mayor se da, no sólo en la falta de lineamientos y procedimientos por parte del Estado para el desarrollo de las Técnicas de Reproducción Asistida, con el riesgo que ello pueda generar en la salud de las personas, sino también en la falta de control y supervisión estatal a los centros que brindan estos servicios, que incluye a los Bancos de Esperma y óvulos y de crioconservados; los que al no tener parámetros legales para el desarrollo de esta actividad, han elaborado sus propias guías, documentos y protocolos de atención sin aprobación alguna de autoridad competente ${ }^{6}$.

De esta manera, tenemos que el Ministerio de Salud si bien ha establecido lineamientos de atención para la salud reproductiva, no ha abordado la administración y buena práctica de los procedimientos de TERAS como parte de su política pública; pese a posibilitar el tratamiento y el uso de estas técnicas conforme al artículo $7^{\circ}$ de la Ley General del Salud, que señala: "Toda persona tiene derecho a recurrir al tratamiento de su infertilidad, así como a procrear mediante el uso de técnicas de reproducción asistida, siempre que la condición de madre genética y de madre gestante recaiga sobre la misma persona. Para la aplicación de técnicas de reproducción asistida, se requiere consentimiento previo y por escrito de los padres biológicos. Está prohibida la fecundación de óvulos humanos con fines distintos a la procreación, así como la clonación de seres humanos."

En un artículo de El Comercio del jueves 23 de octubre de 2008 titulado "Hace falta en el Perú una ley de reproducción asistida". Se mencionó que en nuestro país lamentablemente los avances científicos no han ido junto con el desarrollo del marco legal, ello por la dificultad para controlar los centros de fertilidad, en este mismo artículo el Doctor Enrique Varsi señaló lo siguiente: “No cualquier instituto de salud puede dedicarse a temas de fertilidad si no se cuenta con ciertos parámetros administrativos legales y bioéticos. De cada diez parejas que recurren a estas técnicas cuatro son extranjeros y como no hay ley aquí (Perú) puede hacerse lo que se quiere". Afirmó. 


\section{Inexistencia de registro público de procedimiento de Técnicas de Reproducción Humana Asistida Heterólogas}

En nuestro país, los procedimientos médicos de Técnicas de Reproducción Humana Asistida, especialmente la in vitro, se desarrollan principalmente en el sector privado a través de las clínicas y centros privados; los que en muchos casos, cuentan además con Bancos de Semen, Óvulos, y Embriones en estado de crioconservación.

Sin embargo, ante la falta de regulación de estos procedimientos, tenemos que, especialmente en el caso de las Técnicas de Reproducción Humana Asistida Heterólogas en las que interviene un donante de gametos, estos centros cuentan con autonomía no sólo para contactar con los donantes y garantizarles su anonimidad, sino también para quienes reciben esta donación; de forma tal que quienes acceden a estos procedimientos desconocen la identidad de los donantes; y viceversa, pues el donante tampoco conoce la identidad de la pareja o persona que ha recepcionado su material genético. Todo ello, dentro de la libertad contractual de todas las partes intervinientes, frente a la ausencia de una normativa legal que lo regule.

De lo descrito, tenemos que al ser esta información sólo de conocimiento de la entidad que recibe el material genético se tiene que:

Un donante puede efectuar donaciones de su materia genético en diferentes centros de salud, públicos o privados.

- $\quad$ No existe cruce de información de los donantes de gametos entre los centros que realizan estos procedimientos.

- $\quad$ No existe un mínimo o máximo de donaciones por cada donante.

- No se cuenta con un registro único de donantes que centralice la información de los donantes de gametos ni las personas a las que se les haya implantado el material genético o el embrión que lo contiene.

No existen procedimientos que garanticen el acceso a la información de los donantes de gametos por parte de los nacidos de las TERAS heterólogas. 
Los hechos descritos han sido merituados en el Proyecto de Ley № $1722 / 2012-\mathrm{CR}^{7}$, Ley que regula la reproducción asistida, que en su exposición de motivos reconoce la inexistencia de procedimientos y la ausencia de regulación de aspectos que atañen a este tema, que sin embargo, son de práctica común en muchas clínicas a nivel nacional sin que exista al menos una regulación adecuada que proteja tanto a los donantes como a los sujetos activos; proponiendo al efecto como requisito para la aplicación de las técnicas, que estas sólo se lleven a cabo en centros o servicios sanitarios debidamente autorizados para ello por la autoridad sanitaria correspondiente; sugiriendo además la intervención del Estado para compensar la asimetría de información que existe entre quienes acuden a demandar la aplicación de estas técnicas y quienes las aplican.

De esta manera, tenemos que si bien en la actualidad el Registro Nacional de Historias Clínicas Electrónicas ofrece la infraestructura tecnológica especializada en salud que permite al paciente o a su representante legal y a los profesionales de la salud que son previamente autorizados por aquellos, el acceso a la información clínica contenida en las historias clínicas electrónicas dentro de los términos estrictamente necesarios para garantizar la calidad de la atención en los establecimientos de salud y en los servicios médicos de apoyo públicos, privados o mixtos, en el ámbito de la Ley General de Salud; así como brindar información al Sistema Nacional de Salud para el diseño y aplicación de políticas públicas que permitan el ejercicio efectivo del derecho a la salud de las personas; sin embargo, no considera el acceso al conocimiento del origen biológico del nacido, desde el momento en que su historia clínica no contiene información del donante. A ello, se agrega la forma como los centros han implementado el procedimiento médico de extracción de material genérico (semen u óvulos); que no necesariamente puede encontrarse en la misma clínica donde la mujer realiza la intervención sino en un lugar distinto como un Banco de Esperma u Óvulo.

En consecuencia, al no existir normativa respecto a la forma como se deban realizar estos procedimientos y se lleven los registros de datos de todos los intervinientes, tampoco existe responsabilidad por su pérdida; teniéndose así que dicha información no se encuentra garantizada.

De esta manera, tenemos que la reserva de la información es absoluta, desde el momento mismo de su gestación, no sólo para quienes acceden a estas técnicas sino para el nacido de ellas; quien no sólo desconocerá su origen, 
sino que tampoco podrá acceder a él; pues aun cuando este fuera solicitado judicialmente a la clínica donde se hubiera materializado la inseminación, dependerá de la existencia de los registros en los archivos de la entidad.

El proyecto de Ley $\mathrm{N}^{\circ} 1722 / 2012-\mathrm{CR}^{8}$ que regula la reproducción humana asistida propone en su artículo $4^{\circ}$ los requisitos de los centros y servicios de reproducción asistida; estableciendo la obligatoriedad que dicha práctica sea realizada solamente en aquellos que debidamente están autorizados por la autoridad sanitaria; señalando respecto a los datos relativos a la utilización de estas técnicas, que éstos deberán consignarse en historias clínicas individuales, para ser tratadas con las debidas garantías de confidencialidad respecto a la identidad de los donantes, de los datos y condiciones de los usuarios y de las circunstancias que concurran en el origen de los hijos nacidos. No obstante, se tratará de mantener la máxima integración posible de la documentación clínica de la persona usuaria de las técnicas.

\section{Vulneración del derecho a la identidad por la falta de Registro Público de Donantes.}

El derecho a la identidad es un atributo innato del nuevo ser, el mismo que irá desarrollándose y enriqueciéndose a través de toda una vida, pasando por la infancia, adolescencia, juventud y edad adulta, hasta la muerte.

En función a ello, este derecho natural que el ser humano posee por el simple hecho de ser hombre, se constituye como un derecho fundamental que debe ser protegido por todos los poderes del Estado por ser reconocido como derecho inalienable, inviolable e indisponible para el legislador, quien solo puede comprenderlos, interpretarlos y aplicarlos como efectivas normas jurídicas, encontrándose obligado a establecer un sistema procesal para su defensa frente a posibles violaciones provenientes de los poderes públicos o de los particulares.

Visto así, el Derecho a la Identidad lo entendemos como uno de los atributos esenciales de la persona, consagrado en el inciso 1) del artículo $2^{\underline{0}}$ de la Constitución, Política que señala el derecho que tiene todo individuo a ser reconocido estrictamente por lo que es y por el modo como es; es decir, el derecho a ser individualizado conforme a determinados rasgos distintivos, esencialmente de carácter objetivo (nombre, seudónimo, registro, herencia

Proyecto de Ley presentado el 15 de noviembre de 2012 al Congreso de la República por el Congresista Tomás Zamudio Briceño. 
genética, características corporales, etcétera) y aquellos otros que se derivan del propio desarrollo y comportamiento personal, más bien de carácter subjetivo (ideología, identidad cultural, valores, reputación, etc.). Por tanto, cuando una persona invoca su identidad, lo hace para que sea distinguida frente a otras.

Pero, ¿qué sucede con el derecho a la identidad de los niños nacidos mediante el uso de Técnicas de Reproducción Humana Asistida Heteróloga?; ¿está garantizado, protegido y reconocido constitucionalmente su derecho en todos los casos?

La Ley № 26497, Ley Orgánica del Registro Nacional de Identificación y Estado Civil, establece que los actos concernientes al estado civil de las personas en este caso, el nacimiento, se consignarán en el registro civil; y se extenderán en mérito al Certificado de Nacido Vivo del nacido, si se trata de una inscripción ordinaria o de un expediente administrativo, en el caso de una extemporánea.

En lo que respecta al registro del nacimiento en sí, éste se realiza en mérito a la normativa general regulada en el Código Civil ${ }^{9}$ y el Código de los Niños y Adolescentes, y a la especial establecida por RENIEC; en el formato del acta de nacimiento para Oficinas de Registros del Estado Civil ; y para Oficinas Registrales que realizan Registro en Línea ${ }^{10}$.

De lo descrito anteriormente, tenemos que la normativa legal vigente no ha considerado normas para los nacidos por medio de las TERAS, motivo por el cual a estos nacidos se les asigna su identidad de acuerdo al marco legal establecido, que para el caso de las heterólogas se da de la siguiente manera:

\section{a) Nacidos dentro de un matrimonio}

a.1) En el caso del cónyuge por aplicación de la presunción pater is, el registro del nacido por TERA heteróloga con donante anónimo se realiza atribuyéndole la paternidad, lo que no le debe representar ningún problema para el cónyuge en la medida en que haya dado su consentimiento para el procedimiento de TERA.

Formato de acta de nacimiento aprobado por Resolución Jefatural № 442-2011-JNAC/RENIEC.

Formato de acta de nacimiento aprobado por Resolución Jefatural № 339-2011-JNAC/ RENIEC. 
Pero, ¿qué pasa en aquellos casos en que el marido no ha dado su consentimiento para la inseminación a su cónyuge?. En aplicación de la presunción pater is, igualmente se le atribuye la paternidad del nacido, debiendo recurrir al Poder Judicial mediante la acción de negación de paternidad contenida en el art $363^{\circ}$ del Código Civil para acreditar que el nacido no es su hijo; afectándose no sólo de esta manera al cónyuge sino también al nacido en su derecho a la identidad.

a.2) En el caso de la cónyuge, el registro del nacido puede presentar tres situaciones:

a.2.1) Que el hijo de ambos nazca en el vientre de una madre sustituta.

a.2.2) Que el cónyuge aporte su esperma y el óvulo de una donante sea fecundado (en probeta) y ello sea trasferido a una tercera persona.

a.2.3) Que el cónyuge aporte su esperma y el óvulo sea fecundado con el óvulo de una donante (en una probeta) y ese embrión sea trasferido al útero de su esposa.

En la primera situación (que el hijo de ambos nazca en el vientre de una madre sustituta), el registro del nacimiento se va a dar consignando como madre legal a la madre sustituta.

Así tenemos el proceso judicial de Impugnación de Maternidad seguido ante el Décimo Quinto Juzgado Especializado de Familia de Lima ${ }^{11}$; por una hija contra su madre y esposo a efectos que el órgano jurisdiccional declare que la menor D.M.A. era su hija al haber sido concebida por su persona y por su esposo pero nacida en el vientre de su madre (abuela); pretensión que fue amparada, disponiéndose la rectificación de los apellidos de la niña como D.M.S.

En el segundo supuesto (que el cónyuge aporte su esperma y el óvulo de una donante sea fecundado (en una probeta) y ello sea trasferido a una tercera persona (la cónyuge), el registro de nacimiento se va a realizar tomando como padre al cónyuge; y como madre a la cónyuge, al ser ella la madre que pare, a pesar que en la realidad no sea la madre biológica.

En el tercer supuesto en cambio (que el cónyuge aporte su esperma y el óvulo sea fecundado con el óvulo de una donante (en una probeta) y ese embrión sea transferido al útero de una tercera persona), el registro de

1 Expediente № 183515-2006-00113, confirmado por la Sala de Derecho Constitucional y Social Permanente- Corte Suprema de Justicia de la República. 
nacimiento se puede realizar de diferentes maneras, de acuerdo al estado civil de la madre biológica y portadora; pues si esta es soltera el registro del nacimiento se realizará con los datos de ambos progenitores, los del cónyuge aportante de esperma y los de ella por ser la donante del óvulo y madre portadora); en cambio, si es casada, en aplicación de la presunción pater is el registro de nacimiento se realizará considerando los datos de su cónyuge al igual que si es conviviente y declara a éste como padre; supuesto este último con el que estamos en total desacuerdo pues bajo un contrato de maternidad subrogada en el fondo se está conviniendo la venta del propio hijo de la madre subrogada.

\section{b) Nacidos en una unión de hecho}

b.1) En el caso del conviviente será declarado padre sólo si efectúa el reconocimiento del nacido por TERA heteróloga; pues a él no se le aplica la presunción pater is.

b.2) En el caso de la conviviente, se pueden presentar las mismas situaciones descritas para el caso de la cónyuge; siempre que el conviviente aporte su esperma.

\section{c) Nacidos de madre sola}

El registro de nacimiento se realizará con los apellidos de la madre; sea que use esperma donado; u óvulo donado; siempre que ella sea también la madre portadora.

Tenemos entonces que el derecho a la verdad que forma parte de un más amplio derecho a la justicia, resulta también de aplicación al caso puntual de los nacidos de las TERAS, fundamentalmente de las Heterólogas con donante anónimo al negárseles su derecho al conocimiento de la verdad de su origen.

Sobre el particular, resulta importante destacar también que en estos casos, el derecho a la verdad va de la mano con el derecho a la igualdad; que se constituye también como un derecho constitucionalmente protegido porque los seres humanos son iguales en dignidad y derechos. En consecuencia, si los nacidos por métodos naturales e incluso los adoptados tienen el derecho de conocer a sus progenitores ¿por qué negárselos a los nacidos mediante TERAS Heterólogas?. El hacerlo ¿constituye la violación de su derecho a la igualdad con los otros nacidos y se configura un trato discriminatorio?. 
Nótese entonces como el adoptado, a diferencia del nacido de TERAS Heterólogas, no sólo podrá tener acceso al conocimiento de su origen biológico sino también a los nombres completos de sus progenitores si dicha información apareciera en su acta de nacimiento primigenia; pudiendo ubicar incluso a quienes fueron antes de la adopción sus padres biológicos; sin que ello implique el restablecimiento de sus derechos filiatorios con respecto a esto padres; pudiendo incluso el adoptado al alcanzar la mayoría de edad o al cesar su incapacidad, solicitar que se deje sin efecto la adopción dentro del año siguiente, conforme lo estipula el artículo $385^{\circ}$ del Código Civil, debiendo el Juez de la causa declararla sin más trámite, recuperando en dicho supuesto la vigencia de su filiación consanguínea y la partida correspondiente.

Entonces si ambas figuras persiguen una misma finalidad ¿Cual es la integración plena del adoptado (nacido) en su familia adoptiva (por TERA)? ¿No se debe permitir entonces también al nacido al alcanzar la mayoría de edad o al cesar su incapacidad el conocimiento de su origen biológico e incluso entablar lazos afectivos con su progenitor si así lo decidieran?

En Reino Unido por ejemplo, existe una ley que obliga a dar información no-identificativa sobre la donación a los niños concebidos mediante donación de gametos cuando éstos cumplen la edad de 18 años. En Suecia, los individuos que han sido concebidos por donación de gametos tienen incluso derecho a información identificativa, lo que les permite contactar al donante cuando se hacen mayores. Conociendo también su origen étnico y las eventuales enfermedades genéticas de sus padres biológicos. ${ }^{12}$

Estas leyes se han impuesto debido a que los estudios demuestran que, para algunas personas al menos, el conocimiento sobre sus orígenes es importante para el desarrollo claro de un sentimiento de identidad. Testimonio de ello, son los casos de algunos nacidos de estas TERAS como Margaret R. Brown, la primera niña probeta con esperma donado, quien hoy es una joven y brillante estudiante de biología de Yale. Y reflexiona: «El problema radica en que la inseminación artificial responde al interés de la intimidad de los padres y el médico, en vez de al interés del niño (...) Pero un hijo no es una mercancía ni una propiedad, es una persona que tiene sus propios derechos». ${ }^{13}$

Otro caso es el de Karina Clark quien creció hasta los 17 años sin saber quién era su padre, pero sentía una crisis de identidad y empezó a buscar a su

Derecho a procrear en: http:/ / documents.mx/documents/derecho-a-procrear11.html

Artículo publicado en Aceprensa (1994), obtenido de la página web https://www.aceprensa.com/m/articles/aqui-n-me-parezco/ 
padre biológico como lo afirmó en una entrevista publicada en el diario The Washington Post ${ }^{14}$ cuando tenía 18 años. En dicha entrevista, Karina se manifiesta diciendo: "Me molesta que todo lo relativo a la donación de gametos se centre solo en 'los padres', es decir, los adultos que pueden tomar decisiones sobre nuestras vidas. Se simpatiza con la madre por querer tener un hijo. El donante consigue garantía de anonimato, así como exención de cualquier responsabilidad sobre el hijo nacido de su donación. Mientras estos adultos sean felices, la concepción por donación es un éxito, ¿no?". No es así de simple, contesta ella misma, para recordar acto seguido que los nacidos de manera artificial también son personas. Por eso lucha para que se reconozca su derecho a saber quiénes son sus padres.

Desde el punto de vista emocional -sigue explicando-, muchas de las personas así nacidas sufren en esta situación. "No pedimos nacer de este modo, con las limitaciones y la confusión que implica. Es hipócrita que tanto padres como médicos supongan que a los 'productos' del banco de semen no les interesa conocer sus raíces biológicas, cuando es el vehemente deseo de tener descendentes biológicos lo que hace que los clientes recurran a la inseminación artificial".

En su artículo, Katrina explica además distintos sucesos que le hicieron añorar la figura de un padre que la cuidase y protegiera; lo que la llevó finalmente a su búsqueda. Así que empezó a investigar en Fairfax Cryobank, el banco de esperma de Virginia donde su madre fue inseminada. Con la limitada información que tenía su madre sobre el donante (raza, algunas características físicas, peso, nivel de estudios) fue haciendo averiguaciones. Solo al cabo de un mes de e-mails y búsquedas en Internet, encontró un donante que podía ser su padre y que aceptó hacerse una prueba de ADN. Los resultados confirmaron que era su padre biológico. "Mi vida cambió desde entonces", comenta la propia Katrina.

\section{Afectación a la atención de salud del nacido de TERAS por la falta de Registro Público de Donantes.}

Por nuestra condición humana, existen enfermedades que se transmiten de padres a hijos con motivo de la herencia, que es el proceso por el cual determinados rasgos o características se transmiten genéticamente de padres a hijos y que condiciona el parecido de los individuos pertenecientes a una misma familia. Implica la separación y recombinación de genes

Artículo publicado en The Washington Post (17-12-2006), obtenido de la página web http:/ / www.aceprensa.com/ articles /mi-padre-fue-un-anonimo-donante-de-semen/ 
durante la meiosis y fertilización y la posterior interacción de las influencias del desarrollo y el material genético durante la embriogénesis. (Enciclopedia Mosby de Medicina y Enfermería, 1996).

De esta manera, se tiene que un individuo puede desarrollar anomalías congénitas, presentes en el momento del parto, que puede haber sido heredada genéticamente; al que se le conoce como un defecto innato. Ello es así, debido a que una parte del componente hereditario es la Herencia Autosómica, que se constituye como un patrón de herencia en que la trasmisión de rasgos depende de la presencia o ausencia de ciertos genes en los autosomas. El patrón puede ser dominante o recesivo, y afectan con igual frecuencia a los varones y las mujeres. Se puede decir entonces que la mayoría de los trastornos heredados son consecuencia de genes defectuosos de un autosoma.

Para describir este patrón, diremos que como consecuencia de la Herencia Autosómica Dominante la trasmisión de un gen dominante de un autosoma hace que se manifieste un determinado carácter que va a afectar a la mitad de los descendientes de un progenitor heterocigoto que posea el gen en cuestión y a toda la descendencia de un progenitor homocigoto. Dichos rasgos pueden buscarse verticalmente a través de generaciones previas. Un ejemplo de este tipo de herencia la encontramos en la acondroplasia, que es una enfermedad familiar con alteración del desarrollo del cartílago de crecimiento de los huesos largos y del cráneo que da lugar a su osificación prematura con limitación permanente del desarrollo esqueléctico y enanismo caracterizado por una frente prominente y brazos y piernas gruesos y cortos con un tronco normal; o la osteogénesis imperfecta, que es un transtorno genético que comprende un desarrollo anómalo del tejido conectivo, que se caracteriza por huesos anormalmente quebradizos y frágiles que se fracturan con facilidad por los traumatismos más ligeros.

Para una mejor comprensión de ello, tenemos el caso de Henrik Koch ${ }^{15}$, donante de esperma danés de 60 años de edad a quien se le diagnosticó un cáncer hereditario que causa la enfermedad llamada síndrome de Lynch en 1997, que se desarrolla en el portador entre las edades de 30 y 50 años. Tras el diagnóstico, Koch dijo a las autoridades de salud que había sido previamente un donante de esperma lo que significaba que cualquier niño que pueda haber engendrado tendría ahora un 50 por ciento de posibilidades de ser afectado por la enfermedad. A su vez, ante el diario Berlingske dijo: "Durante

15 Información obtenida de la página web de IceNews http:/www.icenews.is/2013/03/31/sperm-donor-sparks-ethical-debate/\#axzz4JKJL9lqs 
muchos años me he sentido mal que varios niños han heredado probablemente mi enfermedad sin saberlo" y añadió "No me importa que estoy llamando la atención sobre mí. Si una mujer tiene su hijo genéticamente a prueba y esa prueba previene una enfermedad mortal, entonces vale la pena poner a mí mismo hacia adelante".

Lo expuesto, permite afirmar entonces que el donante de material genético no puede ser visto solamente como un dador de esperma u óvulo sin ninguna otra participación en la vida del nacido; sino que por su importancia en el desarrollo físico del nuevo ser debe garantizarse el acceso a su información si esta fuera necesaria.

\section{Afectación en el ámbito familiar por el desconocimiento de impedimentos matrimoniales.}

Pontes de Miranda (2000) considera que debido a la naturaleza jurídica y el carácter moral del matrimonio la ley establece una serie de requisitos sin cuyo cumplimiento no puede ser legalmente contraído; la falta de cualquiera de esos presupuestos toma el nombre de impedimentos. Por ello, para que un matrimonio pueda ser contraído válidamente es preciso que los contrayentes reúnan ciertos requisitos, garantizando el cumplimiento de los fines, libertad, consentimiento, sanidad, respeto a principios éticos y la estabilidad de la sociedad.

Allí donde falta alguno de esos supuestos, condiciones o requisitos, dice Héctor Cornejo Chávez, existe un impedimento para el matrimonio. Según el Diccionario de la Real Academia Española la palabra impedimento (del latín impedimentum) significa obstáculo, estorbo para algo. Agregándole el adjetivo "matrimonial" implica cada una de las circunstancias que hacen ilícito o nulo el matrimonio.

De esta manera, habiendo impedimento, la persona no está legitimada para contraer matrimonio con la persona indicada en la prohibición legal pero sí puede hacerlo con otras o, en su caso, en circunstancias distintas; como sucedería en el caso de las TERAS Heterólogas en el que el impedimento se tendría por la condición de hermanos; no existiendo impedimento si se contrajese con otra persona.

Por este motivo, los impedimentos matrimoniales constituyen causas de oposición a la celebración por parte de los sujetos legitimados, conforme a los artículos 253 y 254 del Código Civil; y, respecto de cualquier persona, como fundamento de la denuncia de su existencia ante la autoridad competente para celebrar el matrimonio, de acuerdo con el artículo 255 del Código Civil; a fin de evitar que los mismos se celebren como una medida 
preventiva contra las anomalías que pueden presentarse en la vida familiar; sobre todo en el caso de los impedimentos dirimentes porque afectan el fondo o sustancia del matrimonio y determinan la invalidez o nulidad del matrimonio.

Justamente uno de ese tipo, es el impedimento derivado del parentesco que existe entre dos o más personas que descienden unas de otras (parentesco por consanguinidad en línea recta), que conforme al art 242, inciso 1, se encuentra prohibido entre los consanguíneos en línea recta, indefinida e ilimitadamente (padres, abuelos, bisabuelos, tatarabuelos o trastatarabuelos sea con hijo, nieto, bisnieto, tataranieto o chozno); así como el inciso 2 del mismo artículo que consagra el impedimento tratándose de parientes colaterales por consanguinidad en el segundo (hermanos); a los que sanciona con nulidad.

El fundamento del impedimento de consanguinidad es ético-social. Las razones que actualmente justifican el citado impedimento pueden reducirse a razones morales, pues se estima que quienes viven cerca unos de otros y bajo el mismo techo no deben pensar en contraer matrimonio a fin de evitar desórdenes; pensamiento que en forma semejante expresó Santo Tomás de Aquino al manifestar su temor que la permisión del matrimonio entre personas que viven en íntimo contacto familiar representa un gran peligro de conducir el sexo a un afeminamiento inmoral. Sin embargo, también existe una consideración de orden científico o eugenésico que abona a favor de la subsistencia del impedimento: los matrimonios entre parientes próximos son fuente de innumerables taras hereditarias. ${ }^{16}$

Como demostración de ello, tenemos el caso de los alemanes Patrick Stübing y Susan Karolewski quienes sin saber que eras hermanos se casaron y tuvieron 4 hijos dos de los cuales tuvieron retrasos mentales, otro, una pequeña malformación cardiaca y sólo uno de ellos no presentó problemas de salud ${ }^{17}$.

Otro caso es el ocurrido en Gran Bretaña el de dos hermanos mellizos que habían sido separados al nacer, que se enamoraron y se casaron, llegando a descubrir posteriormente su origen y su parentesco; lo que significó que la

16 Manual de derecho civil en: http://www.cse.edu.uy/sites/www.cse.edu.uy/files/documentos/FCEA-DerechoCivil_2011-09-01_lowres.pdf

17 El caso salió a la luz pública a raíz de las denuncias por incesto que obligaron a Patrick a cumplir tres años y un mes de prisión por ese delito; siendo su hermana absuelta por sufrir de un ligero retraso madurativo, según la justicia alemana. Artículo publicado en :

http:/ / www.taringa.net/posts/noticias/14558611/Son-hermanos-y-tienen-cuatro-hijos.html 
Corte Suprema Británica anulara su matrimonio al considerar que el mismo estaba fuera de la ley ${ }^{18}$.

Traducido esto a los nacidos de TERAS, es una realidad que la inexistencia de banco de datos de donantes de material genético está trayendo como consecuencia el incremento de posibilidades de que hayan incestos accidentales no sólo entre medios hermanos sino incluso entre estos con los mismos donantes justamente por el desconocimiento que se tiene acerca de su identidad y de la cantidades de donaciones que éstos han ido realizando.

Para una mejor comprensión de las reales dimensiones de este problema, tenemos el caso de Bertold Wiesner ${ }^{19}$ y su mujer, Mary Barton, quienes fundaron en los años 40 una clínica de reproducción asistida que decía proporcionar el semen de padres seleccionados por su inteligencia. Ahora, dos de aquellos niños han descubierto que son hijos del propio Wiesner y se calcula que pueden ser entre 300 y 600 los hijos del fundador.

El escándalo del caso en los medios británicos, lo han descubierto dos hombres concebidos en la clínica mediante inseminación artificial: el documentalista canadiense Barry Stevens -que guarda un parecido asombroso con Wiesner- y el abogado londinense David Gollancz; quienes luego de la investigación realizada al centro y de los análisis de ADN han confirmado que Wiesner fue el donante del esperma, algo que en la época no estaba prohibido por ley.

Para evitar ello, países como Gran Bretaña, Francia y Suecia limitan la cantidad de niños para los que un donante puede aportar esperma. En España el número máximo autorizado de hijos nacidos con gametos de un mismo donante no debe ser superior a seis; para lo cual se exige a los donantes declarar en cada donación si han realizado otras previas; así como señalar en qué centro se practicaron dichas donaciones; responsabilizando al centro el comprobar de manera fehaciente lo dicho; pues de acreditarse que el número de ellos supera el límite establecido, se deben destruir las muestras; lo que sólo podrá ser viable en la medida en que se cuente con un Registro Nacional de Donantes que sirva de consulta a todos los centros y establecimientos de salud que implementen estas técnicas.

18 La historia salió a la luz en una sesión parlamentaria en la que David Alton, un ex diputado liberal demócrata y miembro independiente de la Cámara de los Lores presentó el caso en medio del debate sobre la ley de fertilidad, que esos días estaba siendo tratada por la Cámara en la que el Gobierno Británico se negaba a incluir en la ley una cláusula para que los certificados de nacimiento digan si un niño fue o no concebido por medio de óvulos o espermatozoides de un donante o una donante. El ex diputado quería que se incluya esta medida para que no se produzcan casos como éste. Y defendió "el derecho de los hijos a conocer la identidad de sus padres biológicos". Artículo publicado en http:/ / edant.clarin.com/diario/2008/01/13/sociedad/s-04802.htm

19 Caso publicado en el Diario El Mundo, España y ubicado en la dirección electrónica http://www.elmundo.es/ elmundo/2012/04/09/internacional/1334000184.html. 
Esta situación nos permite afirmar que la problemática que se viene desarrollando como consecuencia de la aplicación de las TERAS en nuestra sociedad no es vista por el Estado como un problema social; sino solamente como un problema particular de quienes acceden a estas técnicas sin advertir la real afectación que se viene generando a la sociedad y a la familia en particular, institución esta última que paradójicamente el Estado se encuentra obligado a proteger.

\section{Registro Nacional de Cedentes de gametos y embriones como entidad garantista del Derecho a la Identidad}

Una medida para garantizar el acceso a la información de los nacidos mediante las TERAS con donante anónimo sería la creación de una entidad de registro de los donantes de material genético.

El antecedente lo encontramos en la Ley Española № 14/2006 que aprobó la Ley sobre Técnicas de Reproducción Humana Asistida, que en su artículo $21^{\circ}$ dispone la creación del Registro Nacional de Donantes, como un organismo público adscrito al Ministerio de Sanidad y Consumo; definiéndolo como un registro administrativo en el que se inscribirán los donantes de gametos y preembriones con fines de reproducción humana, con las garantías precisas de confidencialidad de los datos de aquellos.

Este registro ${ }^{20}$, cuyos datos se basan en los que sean proporcionados por las comunidade s autónomas en lo que se refiere a su ámbito territorial correspondiente, consignará también los hijos nacidos de cada uno de los donantes, la identidad de las parejas o mujeres receptoras y la localización original de cada uno y otros en el momento de la donación y de su utilización.

Considerando que la ley española estipula que la donación es anónima, se garantiza la confidencialidad de los datos de identidad de los donantes por los bancos de gametos, así como los registros de donantes, facultando a los hijos nacidos el derecho por sí o por sus representantes a obtener información general de los donantes que no incluya su identidad; con excepción de aquellas circunstancias extraordinarias que comporten un peligro cierto para la vida o la salud del hijo o cuando proceda con arreglo a las leyes procesales penales, siempre que dicha revelación sea indispensable para evitar el peligro o para conseguir el fin legal propuesto. Complementariamente a esta norma, el Real Decreto-ley 9/2014 antes citado,

\footnotetext{
20 De acuerdo a lo publicado en la página web del diario español El Mundo, actualizada al 27/05/2013, el Registro de donantes de gametos aún no ha sido implementado, a pesar de que ya desde la primera Ley de Reproducción Asistida de 1988 se exigía una herramienta de este tipo.
} 
ha incluído un capítulo especial referido a los sistemas de información, seguimiento y biovigilancia, que permita el registro no solo de los donantes sino también un sistema de información general y su trazabilidad mediante un sistema de rastreo que incluya la codificación de la información.

En el caso de la legislación francesa, después de la reforma del $22 / 1 / 2002$, se ha reforzado la posibilidad de levantar el secreto de la identidad al facilitar la búsqueda del origen biológico gracias a la creación de un Consejo Nacional de Acceso al Origen Personal (CNAOP), órgano independiente compuesto de magistrados, representantes de asociaciones concernientes al objeto de la ley, y profesionales que tienen conocimiento práctico de los temas en cuestión, con lo cual se busca la protección del nacido y su derecho a la identidad. ${ }^{21}$

En Portugal, el Consejo Nacional de Procreación Medicamente Asistida al ser el órgano encargado de pronunciarse sobre las cuestiones éticas, sociales y legales de la procreación medicamente asistida, es también el que se encarga de custodiar la información de los donantes y los nacidos; brindando información eventual sobre la existencia de impedimentos legales para el matrimonio.

Lo expuesto, revela y resalta que en el Perú se están vulnerando los derechos de los nacidos de las TERAS Heterólogas con donante anónimo al no haberse adoptado normas legales que permitan garantizar el acceso al conocimiento del origen biológico; a pesar que existen importantes esfuerzos en ese sentido como el Proyecto de Ley $N^{\circ} 1722 / 2012-C R$ que en su numeral 5 del artículo $5^{\circ}$ señala que la donación será anónima y deberá garantizarse la confidencialidad de los datos de identidad de los donantes por los bancos de gametos; así como en su caso, por los registros de donantes y de actividad de los centros que se constituyan. Agrega que los hijos nacidos tienen derecho por sí o por sus representantes legales a obtener información general de los donantes que no incluya su identidad. Igual derecho corresponde a las receptoras de los gametos y de los preembriones. Sólo excepcionalmente, en circunstancias extraordinarias que comporten un peligro cierto para la vida o la salud del hijo o cuando proceda con arreglo a las Leyes procesales penales, podrá revelarse la identidad de los donantes, siempre que dicha revelación sea indispensable para evitar el peligro o para conseguir el fin legal propuesto. Dicha revelación tendrá carácter restringido y no implicará en ningún caso publicidad de la identidad de los donantes; norma que coincide en ese aspecto con la Ley Española.

${ }^{21}$ Sentencia del Tribunal Europeo de Drets Humans d' Estrasburg en: http://158.109.129.18/centreantigona/docs/ sentencias/Sent $\%$ C3\%A8ncia $\% 20$ del $\% 20$ Tribunal\%20Europeu $\% 20$ de $\% 20$ Drets $\% 20$ Humans $\% 20 \mathrm{~d}$.pdf 
Para Varsi (2013), el Registro Nacional de Cedentes de Gametos y Preembriones con fines de reproducción humana asistida debe ser un registro único constituido por las bases de datos de cada centro de reproducción que opere en el país y que esté debidamente autorizado por el Ministerio de Salud. Justifica su necesidad, para contabilizar la cesión de material genético de los cedentes; que tenga como característica el ámbito nacional y que proporcione la certeza del número de cesiones y actos realizados. De esta manera, se tendría un registro individual de cada cedente, sus datos generales y un número de clave interno que lo identifique.

Recogiendo lo expuesto, concordamos con Varsi (2013) en que se debe crear el Registro Nacional de Cedentes de Gametos y Preembriones, como un organismo público adscrito al Ministerio de Salud en el cual se registren a todos los donantes de gametos y preembriones con fines de reproducción humana, con las garantías precisas de confidencialidad de los datos de aquellos.

Un avance significativo para lograrlo, es la dación de la Ley № 29733, Ley de Protección de Datos Personales que garantiza el derecho fundamental a la protección de datos personales previsto en el artículo $2^{\circ}$ numeral 6 de la Constitución a través de su adecuado tratamiento en un marco de respeto de los demás derechos fundamentales que en ella se reconocen, de la información contenida en los Banco de Datos Personales de administración privada o pública.

Por lo expuesto, urge la creación y funcionamiento del Registro Nacional de Cedentes de Gametos y Preembriones, para lo cual consideramos que correspondería adoptarse las siguientes acciones:

1. Modificar la sección Tercera, Sociedad Paterno Filial, del Libro III, Derecho de Familia del Código Civil para incluir la filiación de los nacidos de TERAS especialmente de aquellos nacidos de TERAS heterólogas con donante anónimo y la forma de acceso al conocimiento de su origen biológico, tal como se da en el caso de los adoptados; manteniéndose para el supuesto de impedimentos matrimoniales.

2. Que el Ministerio de Salud incorpore en el Certificado de Nacido Vivo en la parte estadística, un ítem que registre el tipo de nacimiento: natural o mediante TERA, y en este último caso, si es homóloga o heteróloga. Ello permitirá que se pueda contar con estadísticas oficiales de los nacidos por TERAS, diferenciándose por cada tipo; que al encontrarse en la parte desglosable del mismo se está 
protegiendo el derecho a la identidad de la madre y del nacido.

3. Que el Ministerio de Salud reglamente la autorización y funcionamiento de los centros de salud públicos y privados que realizan las TERAS, así como los bancos de gametos y preembriones; otorgándoles en ambos casos su autorización de funcionamiento; lo que permitirá además su control y supervisión de manera permanente.

4. Crear el Registro Nacional de Cedentes de Gametos y Preembriones como un organismo público descentralizado del Ministerio de Salud, al cual se remitan de manera electrónica y encriptada las Historias Clínicas del donante, los padres y el nacido, las que deberán custodiadas con las garantías precisas de confidencialidad de los datos de aquellos. Todo ello sobre la base de la confidencialidad de los datos de identidad de todos los que participan en dicho proceso; lo que garantizará el acceso al conocimiento del origen biológico por parte del nacido bajo el cumplimiento de la normativa legal que sobre el particular se emita.

5. El Registro Nacional de Cedentes de Gametos y Preembriones debe estar interconectado con el Registro Nacional de Identificación y Estado Civil - RENIEC, para brindar información sobre la existencia de impedimentos matrimoniales de los nacidos de TERAS, como se da en la adopción. Al efecto, debe tenerse en cuenta que el sistema electrónico de emisión del Certificado de Nacido Vivo es producto del trabajo conjunto del RENIEC y MINSA; de ahí que lo mismo podría extenderse a las Historias Clínicas de dichos nacidos para su interconexión con el acta de nacimiento o el Documento Nacional de Identidad Electrónico (DNIe); de forma tal que permita la búsqueda de impedimentos matrimoniales al momento de celebrar un matrimonio.

\section{REFERENCIAS}

Biblioteca de Autores Cristianos (1993). Tomás de Aquino, Summa Theologica I, Cuestión 42, artículo . Madrid, España.

Brena Sesma, Ingrid. (2011). Algunas consideraciones en torno al Derecho a la Reproducción por medio de inseminación artificial. Revista Jurídica Boletín Mexicano de Derecho Comparado $N^{\circ}$ 82. México : UNAM Recuperado de http://revistas.jurídicas.unam.mx/index.php/derecho-comparado/article/ view/3316/3801 
Canessa Vilcashuamán, Rolando Humberto (2008). "Problemas jurídicos que plantean las técnicas de reproducción humana asistida en la legislación civil peruana". (Tesis para optar el grado de Magíster). Universidad Nacional Mayor de San Marcos. Lima, Perú.

Cárdenas Krenz, Arturo Ronald (2014). El Derecho de las Personas concebidas mediante Técnicas de Reproducción Asistida a conocer su identidad biológica, desde una perspectiva biojurídica. (Tesis para optar el grado de Magister en Bioética y Biojurídica). Universidad San Martin de Porres, Lima, Perú.

Enciclopedia Mosby de Medicina y Enfermería, (1996). Tomos del 1 al 6, Barcelona: Edit Océano.

Mesías Ramírez, Carlos (2004). Derechos de la Persona - Dogmática Constitucional. Lima, Perú: Fondo Editorial del Congreso del Perú.

Ministerio de Salud (2004). Guías Nacionales de Atención Integral de la Salud Sexualy Reproductiva, emitida por la Dirección General deSalud de las Personas.

Ministerio de Salud (2010). Directiva Administrativa Nº 166-MINSA/OGEI-V.01, aprobada por Resolución Ministerial N 766-2010/MINSA

Miranda, Pontes (2000). Tratado de Direito Privado $1^{\circ} \mathrm{ed}$, Tomo VII, Campinas, Sao Paulo: Bookseller.

Mosquera Vásquez y Clara Celinda (2010). Las Técnicas de Reproducción Asistida en los Tribunales Peruanos. Diálogo con la Jurisprudencia $N^{\circ} 147$, Editorial Gaceta Jurídica, 146p.

Perez Monge, Marina (2002). La Filiación derivada de Técnicas de Reproducción Asistida. Madrid, España : Fundación Beneficentia-Et Peritia Iuris.

Puccinelli, Oscar (2012). Protección de Datos de carácter personal. Buenos Aires, Argentina: Editorial Astrea, Lavalle.

Valverde Morante, Ricardo (2001). Reflexiones jurídicas planteadas por las Técnicas de Reproducción Humana Asistida. Lima, Perú: Gráfica Horizonte.

Varsi Rospigliosi, Enrique (1995). Derecho Genético. Principios Generales. Trujillo, Perú: Editora Normas Legales.

Varsi Rospigliosi, Enrique (2013). Derecho Genético. Principios Generales. Lima, 
Perú: Editora Grijley.

Varsi Rospigliosi, Enrique (2012). Tratado de Derecho de Familia - Matrimonio y Uniones Estables, Tomo II. Lima, Perú : Gaceta Jurídica S.A.

Varsi Rospigliosi, Enrique (2013). Tratado de Derecho de Familia - Derecho de la Filiación, Tomo IV. Lima, Perú: Gaceta Jurídica S.A.

Vila-Coro Barrachina, María Dolores (1995). Introducción a la Biojurídica. Madrid, España: Servicio de Publicaciones - Facultad de Derecho, Universidad Complutense.

Fecha de recepción: 31 de agosto de 2017 Fecha de aceptación: 18 de setiembre de 2017 